\title{
Medical Therapy of Constipation: Current Standards and Beyond
}

\author{
Viola Andresen Peter Layer \\ Israelitic Hospital, University of Hamburg, Hamburg, Germany
}

Keywords

Laxatives · Prucalopride - Linaclotide - PAMORA · OIC

\section{Summary}

Chronic constipation is a very common medical problem with relevant impact on the patients' quality of life. Modern definitions recognize constipation as a polysymptomatic disorder, including various aspects of disturbed defecation. Current guidelines recommend a stepwise approach in the management of chronic constipation. Isolated or concomitant evacuation disorders should be identified and may need differential/additional treatment. Baseline measures include lifestyle components and bulking agents. The next step recommends treatment with conventional laxatives. In refractory patients, modern medical therapies, such as the prokinetic prucalopride or the secretagogues linalotide or lubiprostone, may be used effectively. For patients with opioid-induced constipation, the modern concept of peripherally acting $\mu$-opioid antagonists has shown to successfully improve this increasing medical problem and even to potentially increase survival time in terminally ill patients on opioid therapy. Prolonged-released oral naloxone (in fixed combination with oxycodone), oral naloxegol or naldemedine, and subcutaneous methylnaltrexone have all demonstrated good efficacy and tolerability in the treatment of opioid-induced constipation. To adequately apply stepwise treatment algorithms, a simple tool to identify treatment failure may improve patient care.

(c) 2018 S. Karger GmbH, Freiburg

\section{Introduction}

Chronic constipation is a very common medical problem. Depending on the definition, up to $15 \%$ of the general German population report symptoms of constipation, matching pooled prevalence rates of $14 \%$ across 18 other countries [1]. Prevalence rates are typically higher for women compared to men (2:1) and increase with age. In the past, constipation was often solely defined by reduced stool frequency (e.g. <3 bowel movements/week). Modern definitions, such as the new Rome IV definition [2] (table 1), recognize constipation as a polysymptomatic disorder including various aspects of disturbed defecation. A variety of primary and secondary disturbances of bowel functions (motility, secretion, sensitivity) or of defecation may lead to constipation. Quality of life may be substantially reduced in affected patients. On the other hand, patients may have to face prejudices that their constipation is just a simple lifestyle problem caused by 'wrong behavior' such as inadequate nutrition, insufficient fluid intake, and lack of physical activity. The establishment of medical guidelines and the development of new therapies may improve not only the treatment strategies but also the recognition of constipation as a relevant medical problem for many patients. The following article will cover current treatment standards and potential future treatment options.

\section{Medical Therapy of Constipation}

\section{Baseline Measures Including Fiber}

For the treatment of constipation, the German S2k consensus guideline recommends a stepwise approach (fig. 1) [3]. Baseline management includes the evaluation and potential modification of lifestyle factors, such as nutritional fiber, fiber supplements, bulking agents, sufficient fluid intake, and regular, moderate physical activity. However, evidence levels for these measures are low, and while patients with mild or habitual constipation may experience 


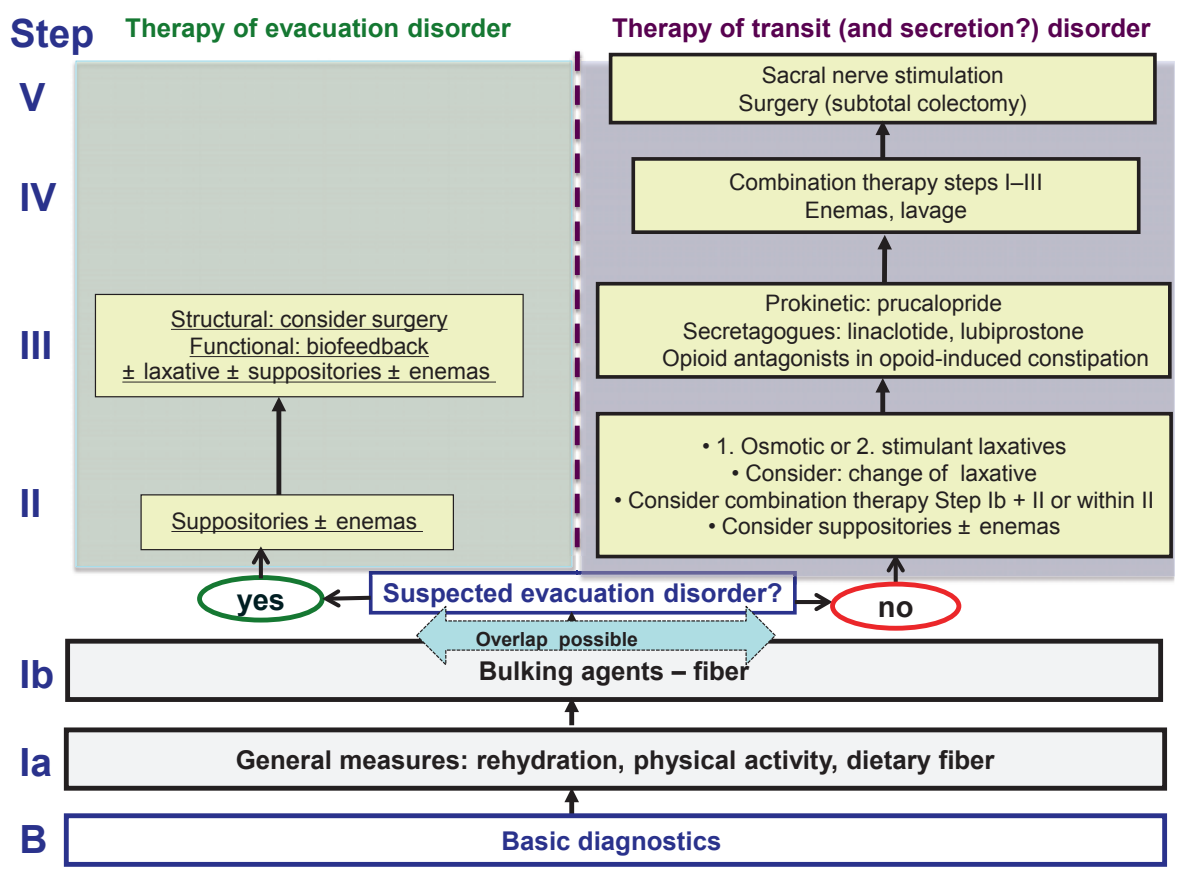

Fig. 1. Stepwise approach in the management of chronic constipation (modified from [3]).

Table 1. Diagnostic criteria for functional constipation [2]

1. Must include two or more of the following:

a. Straining during more than one-fourth $(25 \%)$ of defecations

b. Lumpy or hard stools (BSFS 1"2) more than one-fourth (25\%) of defecations

c. Sensation of incomplete evacuation more than one-fourth (25\%) of defecations

d. Sensation of anorectal obstruction/blockage more than one-fourth (25\%) of defecations

e. Manual maneuvers to facilitate more than one fourth (25\%) of defecations (e.g., digital evacuation, support of the pelvic floor)

f. Fewer than 3 spontaneous bowel movements per week

2. Loose stools are rarely present without the use of laxatives

3. Insufficient criteria for irritable bowel syndrome

${ }^{a}$ Criteria fulfilled for the last 3 months with symptom onset at least 6 months prior to diagnosis.

some symptom improvement, patients with more severe and chronic constipation rarely have notable beneficial effects.

To decide on further measures, it is important to identify a possible underlying evacuation disorder by a thorough history, a functional digital rectal examination, and, if indicated, further examinations, such as anorectal manometry, defecography, or balloon expulsion test. In patients with evacuation disorders, therapeutic measures to improve defecation, such as suppositories or enemas, biofeedback training in pelvic floor dyssynergia [4], or even surgical measures in structural obstructions, such as rectoceles, should be considered (fig. 1).

\section{Laxatives}

In patients with disturbed motility (and/or secretion), the next therapeutic step comprises conventional laxatives, for which effi- cacy has been demonstrated in several studies and meta-analyses [5]. Regarding osmotic laxatives, the best evidence of efficacy and safety - also for long-term treatment - is available for macrogol, while lactulose is less effective with more side effects, mainly bloating. Stimulant laxatives, such as natriumpicosulfate or bisacodyl, have also proven to be effective and safe in randomized clinical trials, while anthrachinones would only be second choice due to lower quality evidence. Recent studies underline the overall safety of laxative treatment even in elderly patients $[6,7]$, while the potential risk of major side effects, such as dehydration and electrolyte disturbance, appears to be overestimated as long as laxatives are used correctly and with the aim to normalize bowel function without inducing diarrhea.

In the light of the different mechanisms of action, a combination of osmotic and stimulant laxatives or a combination of laxatives with bulking agents may be considered in refractory patients.

\section{Prokinetics and Secretagogues}

In patients with inadequate response to or poor tolerance of conventional laxative treatment, modern medical therapies are indicated.

The prokinetic agent prucalopride acts as a selective agonist of the 5-HT4-receptor and thereby stimulates gastrointestinal motility. Several large phase III trials and meta-analyses have demonstrated a good efficacy of prucalopride in patients with severe, laxative-refractory constipation [8-12]. Significant endpoints included normalization of stool frequency as well as improvement of various constipation symptoms and quality of life [13]. Potential adverse effects - especially at the initiation of therapy - include headache, nausea, and diarrhea. In contrast to previous 5-HT4-agonistic agents, such as cisapride or tegaserod, the highly selective prucalopride has not been associated with any cardiac side effects [14]. The 
initial European Medicines Agency (EMA) approval only covered female patients because the pivotal trials included only few men. Hence, an additional 'only-male' phase III trial was added including 370 men with severe constipation. The primary endpoint, defined as $\geq 3$ complete spontaneous bowel movements/week during a 12 -week period, was reached by $38 \%$ of patients taking prucalopride compared to $18 \%$ in the placebo group ( $\mathrm{p}<0.0001)$ (fig. 2 ) [15].

The positive results of this study led to an extended EMA approval for both women and men with constipation failing prior laxative treatment.

The trial evidence also supports effective and safe long-term treatment of chronic constipation with prucalopride [16].

Other 5-HT4-agonistic compounds, such as velusetrag or naronapride, have also been developed for the treatment of gastrointestinal motility disorders and have proved efficacy in chronic constipation [17].

\section{Secretagogues}

Linaclotide is the first-in-class selective guanylate cyclase $\mathrm{C}$ (GC-C) agonist with secretory and visceral antinociceptive properties. It binds locally to GC-C receptors on the surface of intestinal

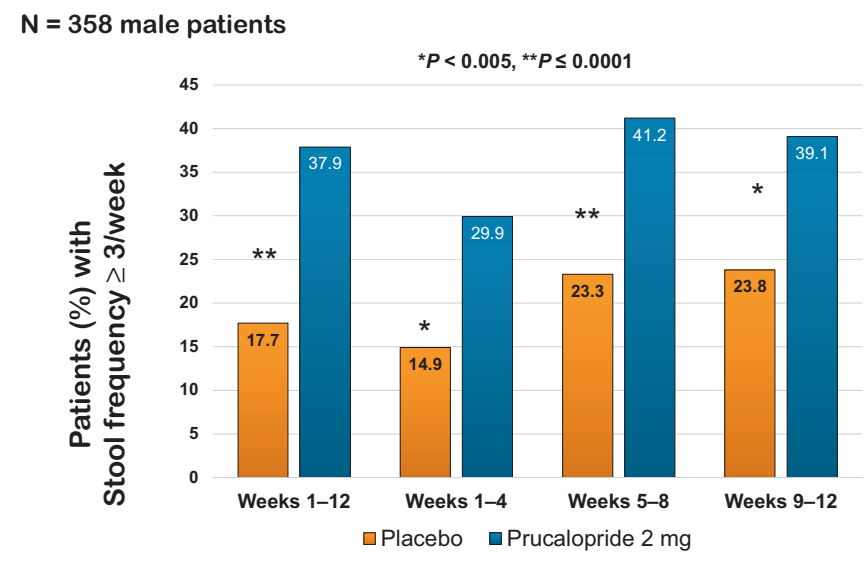

Fig. 2. Significant effect of prucalopride on normalization of stool frequency in patients with severe constipation (modified from [15]). epithelial cells and thereby induces intracellular cyclic GMP (cGMP). On the one hand, this leads to activation of the cystic fibrosis transmembrane conductance regulator (CFTR) with stimulation of water, bicarbonate, and electrolyte secretion into the intestinal lumen, leading to soft stool consistency and increased stool frequency [18]. On the other hand, linaclotide has also been shown to reduce visceral pain, possibly also mediated by cGMP [19].

Linaclotide has been evaluated in a large clinical trial program both for chronic constipation (at a dose of $145 \mu \mathrm{g}$ ) and for constipation-predominant irritable bowel syndrome (IBS-C) (at a dose of $290 \mu \mathrm{g}$ ), demonstrating significant and clinically relevant efficacy in improving both the broad variety of constipation symptoms as well as abdominal pain and bloating [20-24] (fig. 3). Diarrhea has been detected as the only relevant adverse effect leading to treatment cessation in some of the patients. Since the incidence of diarrhea is dose-related, a lower dose of linaclotide $(72 \mu \mathrm{g})$ has been developed and marketed in the USA. In Europe, however, linaclotide is only licensed for IBS-C and is only available at a dose of $290 \mu \mathrm{g}$.

In Germany, linaclotide marketing was stopped for a while due to reimbursement issues, but it has recently been reintroduced in a large packaging size (112 capsules/package). Smaller packaging sizes for new treatment initiations may be imported from other European countries via international pharmacy.

Another GC-C agonist, plecanatide, has demonstrated a similar efficacy and safety as linaclotide $[25,26]$ and has recently been approved by the Food and Drug Administration (FDA) for the treatment of chronic constipation and IBS-C in the USA.

Lubiprostone is a chloride channel activator approved in the USA, in the UK, and in Switzerland for chronic constipation, and for IBS-C (in the USA only). Its mode of action involves induction of water and chloride secretion into the intestinal lumen, leading in turn to decreased stool consistency as well as increased stool volumes and stool transit velocity. Lubiprostone has been shown to be clearly more effective than placebo in several studies and meta-analyses [27], and has been associated with reports of possible adverse effects including diarrhea, nausea, and abdominal cramps.
Fig. 3. Effects of linaclotide on stool frequency in patients with constipation-predominant irritable bowel syndrome (phase III study, $12+4$ weeks, $\mathrm{n}=800$ patients, $\mathrm{CSBM}=$ complete spontaneous bowel movement) (modified from [38]).

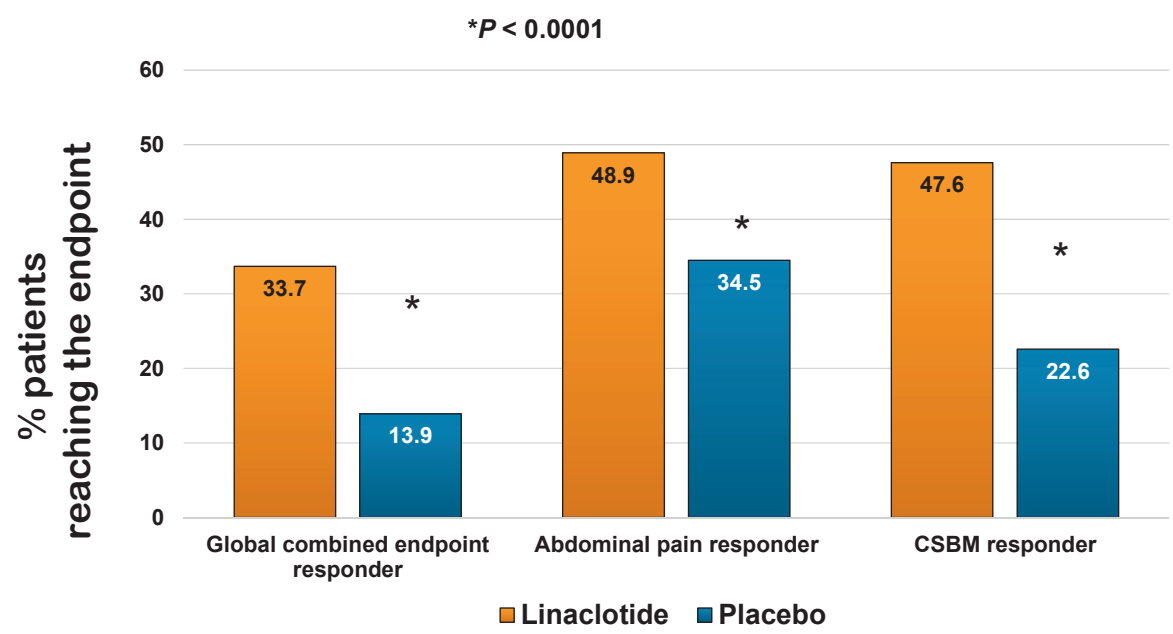

Visc Med 2018;34:123-127 


\section{Peripherally Acting $\mu$-Opioid Antagonists (PAMORA) for Opioid-Induced Constipation}

Opioids play a significant role in the management of chronic pain. Their mode of action is based on activation of central nervous $\mu$-opioid receptors but also involves activation of $\mu$-opioid receptors in peripheral structures. These latter effects in turn are the cause for most classical opioid-associated side effects, the most important of which is opioid-induced constipation (OIC). This is a clinically highly relevant problem compromising opioid therapy, and is explained by the crucial role of opioid receptors in the enteric neural regulation of intestinal motility and secretion.

As a result, patients may experience greater loss of quality of life by severe OIC than by their underlying pain. This difficult clinical challenge is exacerbated by the observation that the efficacy of conventional laxatives is often limited in OIC therapy.

Modern treatment concepts therefore aim to target the underlying pathomechanism of OIC by selectively blocking the opioid effects on intestinal $\mu$-opioid receptors and thus reduce/prevent gastrointestinal side effects without disturbing central (analgetic) effects of opioids [28].

One option is the oral prolonged-release (PR) form of naloxone. Naloxone is a systemic opioid antagonist; however, in oral application, its main action is limited to the intestinal $\mu$-receptors due to a high first-pass-effect in the liver. PR-naloxone is currently available in a fixed-combination tablet with the opioid pain agent oxycodone. This fixed-combination has proven efficacy in pain therapy with concomitant reduction/prevention of OIC [29]. Shortcomings of this approach include the inherent rigidity with regard to application of substances, routes of administration, and dosages, as well as the need for adequate liver function to prevent systemic exposure of naloxone.

The introduction of true peripherally acting $\mu$-opioid antagonists (PAMORA), which do not pass the blood-brain barrier, has therefore significantly enriched the treatment options of OIC, as they can be combined with all types and administration routes of opioid pain medication.

In Europe, currently available PAMORAs are naloxegol, an oral tablet, and methylnaltrexone as subcutaneous application (in the USA also licensed as an oral preparation). In phase III studies, both substances have been shown to be highly effective and tolerable [30-32]; both drugs may be combined with all available opioid regimes irrespective of the choices of substance, medication routes, or dosing.

A new oral PAMORA, naldemedine, which has also demonstrated good efficacy and tolerability in a large clinical trial program [33-35], has recently been approved by the FDA and is currently undergoing licensing application at the EMA.
Table 2. Criteria of treatment failure of constipation [37]

Failure to provide adequate relief may be assumed if any 1 of the following

5 statements applies to the patient during the last 1 or 2 weeks:

- Inadequate number of bowel movements reported by the patient most of the time and complete bowel movements $<3$ days per week.

- Need to strain on most occasions (or straining is getting worse)

- No improvement ${ }^{\mathrm{a}}$ in stool consistency on current therapy and the Bristol

Stool Scale score is less than 3 (hard and lumpy or very hard and small)

- Insufficient improvement ${ }^{a}$ of other signs and/or symptoms of chronic constipation on current treatment.

- Poor tolerability of current treatment makes the relief provided unacceptable.

aThe terms 'no or insufficient improvement' includes 'worsening'.

Introduction of PAMORAs into the treatment armamentarium of chronic pain syndromes has shown to be a major advance, as they eliminate or substantially mitigate OIC as the most frequent and most relevant side effect of chronic opioid therapy. Moreover, it has been shown that effective treatment of OIC may prolong survival in opioid-treated cancer patients [36].

\section{Assessment of Treatment Failure}

Chronic constipation is managed in many cases by the patients themselves or in primary care; however, rates of objective treatment success and subjective patient satisfaction with treatment outcomes are low, and patients with unresponsive symptoms should be referred to secondary care. To support and ensure this referral process and to initiate more intensive medical therapy as recommended by treatment algorithms [3], it is necessary to determine criteria for inadequate constipation relief. Such criteria have been proposed by a recent international expert consensus [37] addressing this important issue (table 2).

As it is crucial for effective management of chronic constipation to discern, and respond to, evidence of inadequate therapeutic relief, this compilation may provide a workable definition of treatment failure, and should be useful in clinical practice to evaluate (the extent of) therapeutic success. Moreover, it may be used as a standardizing calibration tool in the context of clinical trials [37].

\section{Disclosure Statement}

Speaker and/or consulting fees: VA: Allergan, Boehringer Ingelheim, Ferring, KyowaKirin, Nordmark, Shionogi; PL: Allergan, Abbott, Abbvie, Falk, Ardeypharm, Nordmark, Norgine.

\section{References}

1 Enck P, Leinert J, Smid M, Kohler T, Schwille-Kiuntke $\mathrm{J}$ : Prevalence of constipation in the German population - a representative survey (GECCO). United European Gastroenterol J 2016;4:429-437.
2 Mearin F, Lacy BE, Chang L, et al: Bowel disorders. Gastroenterology 2016;DOI: 10.1053/j.gastro.2016.02.031.

3 Andresen V, Enck P, Frieling T, et al. S2k guideline for chronic constipation: definition, pathophysiology, diagnosis and therapy (Article in German). Z Gastroenterol 2013;51:651-672.
4 Skardoon GR, Khera AJ, Emmanuel AV, Burgell RE: Review article: dyssynergic defaecation and biofeedback therapy in the pathophysiology and management of functional constipation. Aliment Pharmacol Ther 2017;46:410-423. 
5 Ford AC, Suares NC: Effect of laxatives and pharmacological therapies in chronic idiopathic constipation: systematic review and meta-analysis. Gut 2011;60: 209-218.

6 Chassagne P, Ducrotte P, Garnier P, Mathiex-Fortunet $\mathrm{H}$ : Tolerance and long-term efficacy of polyethylene glycol $4000\left(\right.$ Forlax $\left.^{\circledR}\right)$ compared to lactulose in elderly patients with chronic constipation. J Nutr Health Aging 2017;21:429-439.

7 Izzy M, Malieckal A, Little E, Anand S: Review of efficacy and safety of laxatives use in geriatrics. World J Gastrointest Pharmacol Ther 2016;7:334-342.

8 Camilleri M, Kerstens R, Rykx A, Vandeplassche L: A placebo-controlled trial of prucalopride for severe chronic constipation. N Engl J Med 2008;358:2344-2354.

9 Quigley EM, Vandeplassche L, Kerstens R, Ausma J: Clinical trial: the efficacy, impact on quality of life, and safety and tolerability of prucalopride in severe chronic constipation - a 12-week, randomized, double-blind, placebo-controlled study. Aliment Pharmacol Ther 2009;29:315-328.

10 Tack J, van Outryve M, Beyens G, Kerstens R, Vandeplassche L: Prucalopride (Resolor) in the treatment of severe chronic constipation in patients dissatisfied with laxatives. Gut 2009;58:357-365.

11 Camilleri M, Piessevaux H, Yiannakou Y, et al: Efficacy and safety of prucalopride in chronic constipation: an integrated analysis of six randomized, controlled clinical trials. Dig Dis Sci 2016;61:2357-2372.

12 Sajid MS, Hebbar M, Baig MK, Li A, Philipose Z: Use of prucalopride for chronic constipation: a systematic review and meta-analysis of published randomized, controlled trials. J Neurogastroenterol Motil 2016;22:412-422.

13 Tack J, Camilleri M, Dubois D, Vandeplassche L, Joseph A, Kerstens R: Association between health-related quality of life and symptoms in patients with chronic constipation: an integrated analysis of three phase 3 trials of prucalopride. Neurogastroenterol Motil 2015;27:397-405.

14 Mendzelevski B, Ausma J, Chanter DO, et al: Assessment of the cardiac safety of prucalopride in healthy volunteers: a randomized, double-blind, placebo- and positive-controlled thorough QT study. Br J Clin Pharmacol 2012;73:203-209.

15 Yiannakou Y, Piessevaux H, Bouchoucha M, et al: A randomized, double-blind, placebo-controlled, phase 3 trial to evaluate the efficacy, safety, and tolerability of prucalopride in men with chronic constipation. Am J Gastroenterol 2015;110:741-748.

16 Dhruva Rao PK, Lewis M, Peiris SP, Shah PR, Haray $\mathrm{PN}$ : Long-term outcome of prucalopride for chronic constipation: a single-centre study. Colorectal Dis 2015;17:1079-1084.
17 Shin A, Camilleri M, Kolar G, Erwin P, West CP, Murad MH: Systematic review with meta-analysis: highly selective 5-HT4 agonists (prucalopride, velusetrag or naronapride) in chronic constipation. Aliment Pharmacol Ther 2014;39:239-253.

18 Andresen V, Camilleri M, Busciglio IA, et al: Effect of 5 days linaclotide on transit and bowel function in females with constipation-predominant irritable bowel syndrome. Gastroenterology 2007;133:761-768.

19 Castro J, Harrington AM, Hughes PA, et al: Linaclotide inhibits colonic nociceptors and relieves abdominal pain via guanylate cyclase-C and extracellular cyclic guanosine 3',5'-monophosphate. Gastroenterology 2013;145:1334-1346.e1-11.

20 Lembo AJ, Kurtz CB, Macdougall JE, et al: Efficacy of linaclotide for patients with chronic constipation. Gastroenterology 2010;138:886-895.el.

21 Quigley EM, Tack J, Chey WD, et al: Randomised clinical trials: linaclotide phase 3 studies in IBS-C - a prespecified further analysis based on European Medicines Agency-specified endpoints. Aliment Pharmacol Ther 2013;37:49-61.

22 Atluri DK, Chandar AK, Bharucha AE, Falck-Ytter Y: Effect of linaclotide in irritable bowel syndrome with constipation (IBS-C): a systematic review and metaanalysis. Neurogastroenterol Motil 2014;26:499-509.

23 Videlock EJ, Cheng V, Cremonini F: Effects of linaclotide in patients with irritable bowel syndrome with constipation or chronic constipation: a meta-analysis. Clin Gastroenterol Hepatol 2013;11:1084-1092.e3; quiz e68.

24 Rao S, Lembo AJ, Shiff SJ, et al: A 12-week, randomized, controlled trial with a 4 -week randomized withdrawal period to evaluate the efficacy and safety of linaclotide in irritable bowel syndrome with constipation. Am J Gastroenterol 2012;107:1714-1724; quiz $\mathrm{p} 25$.

25 Brenner DM, Fogel R, Dorn SD, et al: Efficacy, safety, and tolerability of plecanatide in patients with irritable bowel syndrome with constipation: results of two phase 3 randomized clinical trials. Am J Gastroenterol 2018;DOI: 10.1038/s41395-018-0026-7.

26 Shah ED, Kim HM, Schoenfeld P: Efficacy and tolerability of guanylate cyclase-C agonists for irritable bowel syndrome with constipation and chronic idiopathic constipation: a systematic review and metaanalysis. Am J Gastroenterol 2018;113:329-338.

$27 \mathrm{Li} \mathrm{F}, \mathrm{Fu} \mathrm{T}$, Tong WD, et al: Lubiprostone Is effective in the treatment of chronic idiopathic constipation and irritable bowel syndrome: a systematic review and meta-analysis of randomized controlled trials. Mayo Clin Proc 2016;91:456-468.
28 Ford AC, Brenner DM, Schoenfeld PS: Efficacy of pharmacological therapies for the treatment of opioidinduced constipation: systematic review and meta-analysis. Am J Gastroenterol 2013;108:1566-1574; quiz 75.

29 Blagden M, Hafer J, Duerr H, Hopp M, Bosse B: Longterm evaluation of combined prolonged-release oxycodone and naloxone in patients with moderate-tosevere chronic pain: pooled analysis of extension phases of two Phase III trials. Neurogastroenterol Motil 2014;26:1792-1801.

30 Siemens W, Becker G: Methylnaltrexone for opioidinduced constipation: review and meta-analyses for objective plus subjective efficacy and safety outcomes. Ther Clin Risk Manag 2016;12:401-412.

31 Tack J, Lappalainen J, Diva U, Tummala R, Sostek M Efficacy and safety of naloxegol in patients with opioidinduced constipation and laxative-inadequate response. United European Gastroenterol J 2015;3:471-480.

32 Chey WD, Webster L, Sostek M, Lappalainen J, Barker PN, Tack J: Naloxegol for opioid-induced constipation in patients with noncancer pain. N Engl J Med 2014; 370:2387-2396.

33 Hale M, Wild J, Reddy J, Yamada T, Arjona Ferreira JC: Naldemedine versus placebo for opioid-induced constipation (COMPOSE-1 and COMPOSE-2): two multicentre, phase 3, double-blind, randomised, parallel-group trials. Lancet Gastroenterol Hepatol 2017;2: 555-564.

34 Katakami N, Harada T, Murata T, et al: Randomized phase III and extension studies of naldemedine in patients With opioid-induced constipation and cancer. J Clin Oncol 2017;35:3859-3866.

35 Webster LR, Nalamachu S, Morlion B, et al: Long-term use of naldemedine in the treatment of opioid-induced constipation in patients with chronic non-cancer pain: a randomized, double-blind, placebo-controlled phase 3 study. Pain 2018;DOI: 10.1097/j.pain.0000000000001174.

36 Janku F, Johnson LK, Karp DD, Atkins JT, Singleton PA, Moss J: Treatment with methylnaltrexone is associated with increased survival in patients with advanced cancer. Ann Oncol 2017;DOI: 10.1093/annonc/ $\operatorname{mdx} 776$.

37 Tack J, Boardman H, Layer P, et al: An expert consensus definition of failure of a treatment to provide adequate relief (F-PAR) for chronic constipation - an international Delphi survey. Aliment Pharmacol Ther 2017;45:434-442.

38 Chey WD, Lembo AJ, Lavins BJ, et al: Linaclotide for irritable bowel syndrome with constipation: a 26-week, randomized, double-blind, placebo-controlled trial to evaluate efficacy and safety. Am J Gastroenterol 2012; 107:1702-1712. 